SANTOS, Luana Marina dos. Uma breve análise acerca da crítica hermenêutica do direito frente aos desafios do multiculturalismo. Revista Eletrônica Direito e Política, Programa de Pós-Graduação Stricto Sensu em Ciência Jurídica da UNIVALI, Itajaí, v.16, n.2, $2^{\circ}$ quadrimestre de 2021. Disponível em: www.univali.br/direitoepolitica - ISSN 1980-7791.

\title{
UMA BREVE ANÁLISE ACERCA DA CRÍTICA HERMENÊUTICA DO DIREITO FRENTE AOS DESAFIOS DO MULTICULTURALISMO
}

\author{
A BRIEF ANALYSIS ABOUT THE HERMENEUTIC CRITICISM OF RIGHT IN FRONT
}

OF THE CHALLENGES OF MULTICULTURALISM

\section{Luana Marina dos Santos ${ }^{1}$}

\section{RESUMO}

A sociedade contemporânea é protagonizada, cada vez mais, pela diversidade étnica, cultural e religiosa, em que a temática do multiculturalismo se afigura como um aspecto relevante, principalmente no que diz respeito ao problema de moralidade e da aplicação da ciência jurídica. Diante da pluralidade de culturas autônomas presentes em um mesmo território, esta pesquisa procura transcorrer acerca da problemática da hermenêutica jurídica no que tange às inúmeras possibilidades de interpretações constitucionais realizadas pelo Poder Judiciário. Para isso, objetiva-se explanar sobre o fenômeno do multiculturalismo e seus impactos na comunidade jurídica, e, por fim, identificar como a proposta apontada pelo jurista e professor Lenio Streck pode se apresentar como uma resposta para a harmonização das divergências provenientes de sociedades multiculturais, sem abrir mão dos direitos e garantias fundamentais previstos na Constituição Federal Brasileira de 1988. O método empregado é o indutivo, aliado ao levantamento bibliográfico e documental.

PALAVRAS-CHAVE: Hermenêutica, Multiculturalismo, Integridade.

\section{ABSTRACT}

Contemporary society is increasingly involved in ethnic, cultural and religious diversity, in which the theme of multiculturalism appears as a relevant aspect, especially with regard to the problem of morality and the application of legal science. In view of the plurality of autonomous cultures present in the same territory, this research seeks to discuss the issue of legal hermeneutics in terms of the numerous possibilities for constitutional interpretations carried out by the Judiciary. To this end, the objective is to explain about the phenomenon of multiculturalism and its impacts on the legal community, and, finally, to identify how the proposal pointed out by the jurist and professor Lenio Streck can present itself as an answer for the harmonization of divergences from multicultural societies, without giving up the fundamental rights and guarantees

\footnotetext{
1 Mestranda em Direito pela Universidade do Vale do Rio dos Sinos. Bolsista CAPES/PROEX. Bacharel em Ciências Jurídicas e Sociais pela Universidade do Vale do Rio dos Sinos. São Leopoldo - Rio Grande do Sul. Brasil. E-mail: luanamarinads@gmail.com.
} 
SANTOS, Luana Marina dos. Uma breve análise acerca da crítica hermenêutica do direito frente aos desafios do multiculturalismo. Revista Eletrônica Direito e Política, Programa de Pós-Graduação Stricto Sensu em Ciência Jurídica da UNIVALI, Itajaí, v.16, n.2, $2^{\circ}$ quadrimestre de 2021. Disponível em: www.univali.br/direitoepolitica - ISSN 1980-7791.

provided for in the Brazilian Federal Constitution of 1988. The method used is the inductive, combined with bibliographic and documentary surveys.

KEYWORDS: Hermeneutics, Multiculturalism, Integrity

\section{INTRODUÇÃO}

A interpretação do Direito no interior de sociedades multiculturais é marcada por uma série de divergências conceituais. Os diversos grupos que compõem a sociedade contemporânea protagonizam uma diversidade de padrões que percorrem os campos da religião, do gênero e da sexualidade, da política, da educação, da cultura, e, inclusive, das próprias garantias constitucionais. Impõese, neste cenário, o desafio do Direito: salvaguardar direitos e garantias fundamentais ao mesmo tempo em que procura proteger a diversidade e a aplicação das normas jurídicas em uma sociedade que se considera democrática.

Ainda que um mesmo território contenha uma intensa diversidade de opiniões acerca do conteúdo jurídico do texto normativo, um verdadeiro Estado democrático tem o dever de propiciar uma convivência harmônica entre todos os indivíduos, porquanto é necessário que haja uma postura dos poderes instituídos no que diz respeito à interpretação legislativa no interior de sociedades multiculturais, permeadas, justamente, por tamanha diversidade. É neste sentido que se apresenta o importante papel do Direito na absorção da pluralidade normativa e sociológica na sociedade contemporânea quando da prática hermenêutica do intérprete.

Considerando que a prática da hermenêutica jurídica requer responsabilidade e compromisso com a Constituição, ainda que em alguns casos considerados difíceis não haja uma resposta objetiva proveniente do texto legal, é imperioso ressaltar que, ainda que o Direito procure se adequar às dinâmicas de uma sociedade multicultural, as decisões do hermeneuta não podem - e não devem ter poder de livre convencimento. Cabe ao hermeneuta, neste ponto, evitar fundamentalmente que a decisão dada por este seja objetivada por subjetividade ou ideologia, evitando decisões arbitrárias que não se adequem ao texto 
SANTOS, Luana Marina dos. Uma breve análise acerca da crítica hermenêutica do direito frente aos desafios do multiculturalismo. Revista Eletrônica Direito e Política, Programa de Pós-Graduação Stricto Sensu em Ciência Jurídica da UNIVALI, Itajaí, v.16, n.2, $2^{\circ}$ quadrimestre de 2021. Disponível em: www.univali.br/direitoepolitica - ISSN 1980-7791.

constitucional. Desta forma, apresenta-se a proposta oferecida por Lenio Streck, a fim de que, na medida em que haja a existência de perspectivas multiculturais, também coexista a salvaguarda das normativas previstas no texto constitucional brasileiro, não permitindo a prática arbitrária do aplicador.

Para isso, a partir do método indutivo, aliado ao levantamento bibliográfico e documental, far-se-á, em um primeiro momento, uma breve explanação acerca do multiculturalismo e seus impactos na comunidade jurídica. Na sequência, a partir dos aportes de Lenio Streck e Ronald Dworkin, analisa-se as dificuldades que a hermenêutica jurídica enfrenta quando da aplicação do Direito em sociedades multiculturais, principalmente quando esta se encontra à mercê das influências morais de seus aplicadores. Por fim, debruça-se sobre a proposta oferecida por Lenio Streck, identificando como esta pode se apresentar como uma resposta para a harmonização das divergências provenientes de sociedades multiculturais, sem abrir mão dos direitos e garantias fundamentais previstos na Constituição Federal Brasileira de 1988.

Este trabalho utiliza o método indutivo pois parte de observações específicas para, ao final, sugerir conclusões que podem ser consideradas ou não verdadeiras. Este artigo buscou informações bibliográficas e documentais porquanto se utiliza de referenciais teóricos e da busca de documentos como leis, notícias e reportagens. Impende salientar, ainda, que a presente pesquisa não pressupõe o esgotamento do tema, tampouco sugere uma resposta conclusiva ao objeto que aqui se apresenta, mas sim, propõe explanações pontuais acerca da correlação entre os possíveis impactos provindos do fenômeno do multiculturalismo e da aplicação da hermenêutica jurídica.

\section{O MULTICULTURALISMO E SUAS IMPLICAÇÕES NO MUNDO JURÍDICO}

A diversidade étnica, cultural e religiosa é responsável por protagonizar um dos maiores desafios que o Direito enfrenta em tempos contemporâneos. O multiculturalismo, encarregado de promover vasta pluralidade de culturas em um mesmo território, compõe uma sociedade que, muitas vezes, diverge 
SANTOS, Luana Marina dos. Uma breve análise acerca da crítica hermenêutica do direito frente aos desafios do multiculturalismo. Revista Eletrônica Direito e Política, Programa de Pós-Graduação Stricto Sensu em Ciência Jurídica da UNIVALI, Itajaí, v.16, n.2, $2^{\circ}$ quadrimestre de 2021. Disponível em: www.univali.br/direitoepolitica - ISSN 1980-7791.

radicalmente no que diz respeito à política, à religião, à educação e, especialmente, à própria aplicação das normas jurídicas. No entanto, é justamente nesta vasta diversidade de opiniões, que o Direito encontra seu maior desafio: proteger a diversidade e a aplicação das normas jurídicas em uma sociedade que se considera democrática.

Propiciar uma convivência harmônica entre todas as camadas presentes na sociedade contemporânea se apresenta como tarefa fundamental para uma melhor compreensão do Direito a partir das relações sociais de todas as comunidades $^{2}$. Isso porque, a presença do multiculturalismo também é capaz de gerar uma série de discrepâncias morais, inclusive no que diz respeito aos inúmeros significados semânticos que os próprios Direitos e garantias fundamentais, que se encontram devidamente positivados pela mais recente Constituição Federal Brasileira de 1988, podem promover em diferentes grupos e/ou comunidades ${ }^{3}$.

A Constituição Federal Brasileira de 1988, chamada de Constituição Cidadã, inspirada pela temática democrática, agrega uma série de direitos fundamentais, individuais e sociais, os quais objetivam salvaguardar princípios basilares e essenciais a todos os indivíduos, como, por exemplo, a igualdade e a dignidade da pessoa humana ${ }^{4}$. No entanto, ressalta-se que há uma grave ineficácia deste instrumento normativo, uma vez que a tutela destes direitos nem sempre logra êxito em delimitar sua essência ontológica enquanto objeto social, dada a vasta existência de diferentes grupos sociais na sociedade.

Considerando a presença de uma sociedade multiculturalista, tem-se que, na impossibilidade do reconhecimento da diferença dos grupos sociais que compõem

2 SANTOS, Boaventura de Sousa. (Org.). Reconhecer para libertar. Os caminhos do cosmopolitismo multicultural. Porto, Portugal: Edições Afrontamento, 2004.

3 SANTOS, Boaventura de Sousa. (Org.). Reconhecer para libertar. Os caminhos do cosmopolitismo multicultura, 2004.

${ }^{4}$ Art. $1^{\circ} \mathrm{A}$ República Federativa do Brasil, formada pela união indissolúvel dos Estados e Municípios e do Distrito Federal, constitui-se em Estado Democrático de Direito e tem como fundamentos: I a soberania; II - a cidadania; III - a dignidade da pessoa humana. Art. $5^{\circ}$ Todos são iguais perante a lei, sem distinção de qualquer natureza, garantindo-se aos brasileiros e aos estrangeiros residentes no País a inviolabilidade do Direito à vida, à liberdade, à igualdade, à segurança e à propriedade. BRASIL. Constituição da República Federativa do BrasiL de 1988. Brasília, DF, 1988. Disponível em: https://is.gd/Q7arPx. Acesso em: 11 fev. 2020. 
SANTOS, Luana Marina dos. Uma breve análise acerca da crítica hermenêutica do direito frente aos desafios do multiculturalismo. Revista Eletrônica Direito e Política, Programa de Pós-Graduação Stricto Sensu em Ciência Jurídica da UNIVALI, Itajaí, v.16, n.2, $2^{\circ}$ quadrimestre de 2021. Disponível em: www.univali.br/direitoepolitica - ISSN 1980-7791.

um território nacional, permeia também a impossibilidade de saber quais são os verdadeiros fatores do poder que, pelo menos em tese, deveriam prevalecer. Isso porque, o multiculturalismo presente no mundo contemporâneo caracterizase, de acordo com Boaventura de Sousa Santos ${ }^{5}$, como a coexistência de formas culturais ou de grupos "[...] caracterizados por culturas diferentes no seio de sociedades modernas. Rapidamente, contudo, o termo se tornou um modo de descrever as diferenças culturais em um contexto transnacional e global". Considera-se, portanto, com base em Boaventura, que o multiculturalismo é responsável por protagonizar a coexistência de uma gama de culturas inseridas em um mesmo país ou território.

Diante da presença do multiculturalismo que, conforme Boaventura 6 , está presente no mundo todo - inclusive no Brasil -, é possível questionar acerca do paradigma que envolve os conceitos básicos de determinados direitos e garantias salvaguardados no texto constitucional brasileiro. A problemática de reconhecer a existência de diferentes significados para um mesmo Direito em sociedades tão plurais, abre margem para que o Direito passe a questionar a aplicabilidade de determinados preceitos legais junto às possibilidades e dificuldades de construção de novas culturas em um mesmo espaço territorial.

Conforme Haas ${ }^{7}$, se insere, neste contexto, a necessidade da conciliação da diferença no que diz respeito à aplicabilidade de direitos e garantias, principalmente no que tange aos direitos fundamentais, porquanto estes são os responsáveis por positivar salvaguardas necessárias para uma vida humana digna. No entanto, segundo a autora, dada a coexistência de uma série de culturas inseridas em um único território, pode-se afirmar que a concepção de direitos, como a vida digna, por exemplo, pode lograr êxito em permitir, também, a coexistência de uma série de interpretações, variando de grupo para

\footnotetext{
5 SANTOS, Boaventura de Sousa. (Org.). Reconhecer para libertar. Os caminhos do cosmopolitismo multicultural. Porto, Portugal: Edições Afrontamento, 2004. p. 20.

6 SANTOS, Boaventura de Sousa. (Org.). Reconhecer para libertar. Os caminhos do cosmopolitismo multicultural. p. 20.

7 HAAS, Ingrid Freire. Multiculturalismo na atualidade: o direito à cultura e sua expressão nos direitos humanos. Revista Eletrônica do Curso de Direito - PUC Minas Serro, n. 5, p. 105-127, 2012. Disponível em: https://is.gd/drIXin. Acesso em: 9 fev. 2020.
} 
SANTOS, Luana Marina dos. Uma breve análise acerca da crítica hermenêutica do direito frente aos desafios do multiculturalismo. Revista Eletrônica Direito e Política, Programa de Pós-Graduação Stricto Sensu em Ciência Jurídica da UNIVALI, Itajaí, v.16, n.2, $2^{\circ}$ quadrimestre de 2021. Disponível em: www.univali.br/direitoepolitica - ISSN 1980-7791.

grupo. Assim, os direitos perseguidos para que esta vida digna se concretize também irão, consequentemente, variar conforme o grupo que os reivindique ${ }^{8}$.

Poder-se-ia afirmar, que diante da premissa que envolve o multiculturalismo e a aplicabilidade do Direito posto, nem sempre é possível adequar a ordem legislativa para de acordo com os interesses de todas as culturas existentes. Neste sentido, exsurge-se o desafio do Direito. Assim, para Boaventura de Souza

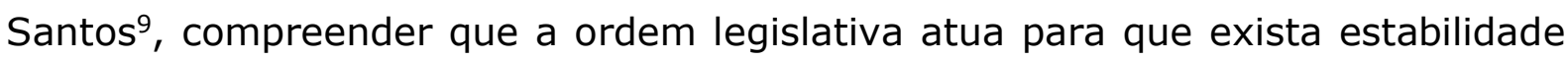
nas relações sociais contemporâneas é passo fundamental para compreender de que maneira - ou em que medida -, este mesmo Direito logra êxito em atuar em consonância com a pluralidade que se estabelece entre as sociedades.

Ocorre que o Direito, ainda que busque solucionar os conflitos individuais e coletivos da sociedade em geral, deixa de ser linear, uma vez que este passa a ter que lidar "[...] não somente com as antigas questões ainda não resolvidas, mas também a tutelar novos conflitos que vêm surgindo"10, especialmente no que tange à pluralidade de entendimentos normativos provenientes da incidência do multiculturalismo. Logo, tendo em vista que o multiculturalismo corresponde à diversidade, "[...] uma vez que aceita diversas opiniões sobre um mesmo tema, abolindo o pensamento único"11, reconhece-se a função primordial do Direito quando necessário para fins de reconhecer tal existência multicultural e, consequentemente, incentivar o diálogo entre os grupos em prol da garantia de uma vida digna, ainda que com conceitos não especificamente definidos.

A percepção do conceito do multiculturalismo carrega consigo, ainda, a noção de respeito às diferenças culturais e a preservação da diversidade cultural de minorias étnicas, livrando-as da forte interferência de culturas hegemônicas. Assim, é possível dizer que esta noção de salvaguarda às diferenças culturais

\footnotetext{
8 HAAS, Ingrid Freire. Multiculturalismo na atualidade: o direito à cultura e sua expressão nos direitos humanos. p. 105-127.

9 SANTOS, Boaventura de Souza. Por uma concepção multicultural de direitos humanos. Revista Crítica de Ciências Sociais, n. 48, p. 11-32, jun., 1997. Disponível em: https://is.gd/b73AxS. Acesso em: 9 fev. 2020.

${ }^{10}$ PEREIRA, Mychelli Araújo de Oliveira. A questão dos direitos fundamentais na atual sociedade multiculturalista. Revista Jurídica ESMP-SP, v.4, p. 43-58, 2013. p. 51. Disponível em: https://is.gd/VuYv1K. Acesso em: 30 jan. 2020.

${ }^{11}$ PEREIRA, Mychelli Araújo de Oliveira. A questão dos direitos fundamentais na atual sociedade multiculturalista. p. 52.
} 
SANTOS, Luana Marina dos. Uma breve análise acerca da crítica hermenêutica do direito frente aos desafios do multiculturalismo. Revista Eletrônica Direito e Política, Programa de Pós-Graduação Stricto Sensu em Ciência Jurídica da UNIVALI, Itajaí, v.16, n.2, $2^{\circ}$ quadrimestre de 2021. Disponível em: www.univali.br/direitoepolitica - ISSN 1980-7791.

recai, também, sob o manto protecionista que rega a salvaguarda dos direitos fundamentais ${ }^{12}$. Permitir que a ordem legislativa possa se adequar no seio da sociedade, e não a partir de um formalismo exacerbado, consente que o Direito possa ser compreendido como um agente efetivo de transformação social, "pois à medida que é capaz de ouvir e conciliar as mais diversas culturas que se encontram unidas pelo sentimento de comunidade e solidariedade, permite também identificar a diferença como agente discriminador positivo"13.

Cumpre esclarecer, no entanto, que mesmo que a mais recente Constituição Brasileira tenha procurado positivar valores e garantias que busquem salvaguardar direitos fundamentais para minorias étnicas, para além do desafio que o Direito enfrenta no que tange à salvaguarda destes direitos e garantias fundamentais em sociedades tão plurais, a comunidade jurídica lida, também, com a falta de eficácia destes mesmos instrumentos normativos ${ }^{14}$. A falta de eficácia destes direitos, de acordo com Streck, se dá, pois, "em nosso país, não há dúvida de que, sob a ótica do Estado Democrático de Direito - em que o Direito deve ser visto como instrumento de transformação social -, ocorre uma desfuncionalidade do Direito e das Instituições encarregadas de aplicar a lei"15.

Assim, considerando que os direitos fundamentais ainda não lograram êxito em atingir a todos os grupos sociais, substancialmente aqueles menos privilegiados, porquanto o Brasil segue apresentando uma série de estatísticas numéricas que apontam para a precária condição de vida das classes mais hipossuficientes ${ }^{16}$, é imperioso destacar que haja, formalmente, a formulação de programas que busquem institucionalizar deveres aos poderes públicos para fins de materializar

\footnotetext{
12 PEREIRA, Mychelli Araújo de Oliveira. A questão dos direitos fundamentais na atual sociedade multiculturalista. p. 51.

13 PEREIRA, Mychelli Araújo de Oliveira. A questão dos direitos fundamentais na atual sociedade multiculturalista. p. 55.

14 STRECK, Lenio Luiz. Jurisdição Constitucional e Hermenêutica: uma nova crítica do Direito. Rio de Janeiro: Editora Forense, 2004.

${ }^{15}$ STRECK, Lenio Luiz. Jurisdição Constitucional e Hermenêutica: uma nova crítica do Direito. p. 16.

16 De acordo com pesquisa realizada em 2018 pelo Fundo das Nações Unidas para a Infância (Unicef), a pobreza no Brasil não está ligada apenas a questões monetárias, mas também à privação de um ou mais direitos, como: educação, informação, proteção contra o trabalho infantil, moradia, água e saneamento. FORTUNA, Deborah; SOARES, Ingrid. Pobreza no Brasil não está ligada apenas a questões financeiras. Correio Braziliense, 15 ago., 2018. Disponível em: https://is.gd/jpptyS. Acesso em: 9 fev. 2020.
} 
SANTOS, Luana Marina dos. Uma breve análise acerca da crítica hermenêutica do direito frente aos desafios do multiculturalismo. Revista Eletrônica Direito e Política, Programa de Pós-Graduação Stricto Sensu em Ciência Jurídica da UNIVALI, Itajaí, v.16, n.2, $2^{\circ}$ quadrimestre de 2021. Disponível em: www.univali.br/direitoepolitica - ISSN 1980-7791.

o apregoado pelo texto normativo no intuito de que estas sejam devidamente cumpridas. Para Streck ${ }^{17}$,

[...] não houve ainda, no plano hermenêutico, a devida filtragem - em face da emergência de um novo modo de produção do Direito representado pelo Estado Democrático de Direito - desse (velho/defasado) Direito, produto de um modo liberal-individualista-normativista de produção de Direito, entendendo-se como um modo de produção de Direito [...]. É importante observar, no meio de tudo isto, que, em nosso país, há até mesmo uma crise de legalidade, uma vez que nem sequer esta é cumprida, bastando, para tanto, ver a inefetividade dos dispositivos da Constituição.

No que tange a isso, sustenta-se a necessidade de uma nova postura dos poderes instituídos do Estado Democrático de Direito no que diz respeito, não somente à eficácia da proteção dos dispositivos constitucionais, mas, também, àquilo que for relativo à interpretação da salvaguarda de direitos e garantias especialmente no que tange à proteção dos direitos fundamentais - no interior de sociedades permeadas pela diversidade de grupos sociais que ocupam um mesmo território nacional, sobretudo quando a tradição e os significados que compõem a salvaguarda destes direitos apresentam inúmeros significados em sociedades multiculturais.

Deste modo, considerando a realidade plural das sociedades contemporâneas, altamente permeadas pela diferença cultural, cabe a estas, cada vez mais, recorrer ao Estado de Direito para suportar seus interesses contrapostos, bem como para lutar para garantir socialmente até mesmo os direitos que já se encontram constitucionalmente positivados. Assim, é diante deste desafio - de garantir o desenvolvimento interpretativo das normas jurídicas em sociedades multiculturais, bem como promover a efetividade das normas constitucionais -, que se apresenta a importância do papel da hermenêutica jurídica, que:

[...] além de dizer o que as normas jurídicas efetivamente significam ou passam a significar ao longo de sua aplicação no tempo, cabe-lhe enunciar os princípios gerais que

17 STRECK, Lenio Luiz. Hermenêutica jurídica $\mathbf{e}(\mathbf{m})$ crise: uma exploração hermenêutica da construção do Direito. p. 33. 
SANTOS, Luana Marina dos. Uma breve análise acerca da crítica hermenêutica do direito frente aos desafios do multiculturalismo. Revista Eletrônica Direito e Política, Programa de Pós-Graduação Stricto Sensu em Ciência Jurídica da UNIVALI, Itajaí, v.16, n.2, $2^{\circ}$ quadrimestre de 2021. Disponível em: www.univali.br/direitoepolitica - ISSN 1980-7791.

presidem a vigência e eficácia das normas jurídicas, bem como conceber os modelos hermenêuticos destinados a preencher as lacunas do sistema normativo ${ }^{18}$.

Não se nega a necessidade de caminhar ao encontro de uma sociedade apta a uma maior interpretação Constitucional, objetivando abarcar a sociedade multicultural que se apresenta. No entanto, se apresenta, na mesma medida, a necessidade de assegurar a verdadeira eficácia e salvaguarda de direitos fundamentais, independente da comunidade na qual estes serão aplicados. Logo, considerando que o papel da hermenêutica é permitir ao poder judiciário imprimir o real desenvolvimento e interpretação das normas constitucionais, verificar-se-á, no próximo capítulo, os desafios enfrentados pela hermenêutica jurídica quando da aplicação de normas legislativas, especialmente no que diz respeito à interpretação moral do exegeta quando inserido em sociedades pautadas pelo multiculturalismo.

\section{HERMENÊUTICA JURÍDICA E SEUS DESAFIOS}

Conforme Streck ${ }^{19}$, "no Direito, podemos dizer que as palavras da lei não são unívocas". Isso quer dizer que as palavras não necessariamente logram êxito em refletir a essência das coisas, razão pela qual, de acordo com o jurista, não basta a palavra da lei. Neste sentido, compreende-se que o sentido da lei só é capaz de existir em um determinado contexto. Ainda de acordo com Streck ${ }^{20}$, "o texto da lei só existe na sua norma; e a norma só existe a partir do seu texto. Nós não inventamos os sentidos. Estamos comprometidos com isso que chamamos de 'mundo'". A partir destes excertos, o jurista explica que o Direito, por si só, é um fenômeno complexo, assim como a realidade. Para o autor ${ }^{21}$,

[...] o mundo não é um quiz show. A realidade também não. Direito é um fenômeno complexo. Não adianta fazer decoreba. Há sempre um a priori que compartilhamos

18 REALE, Miguel. Fontes e modelos do Direito: para um novo paradigma hermenêutico. São Paulo: Saraiva, 1994. p. 107.

${ }^{19}$ STRECK, Lenio Luiz. Hermenêutica. Livro carta. São Leopoldo: Edição do autor, 2017. p. 4.

${ }^{20}$ STRECK, Lenio Luiz. Hermenêutica. p. 5.

${ }^{21}$ STRECK, Lenio Luiz. Hermenêutica.. p. 5. 
SANTOS, Luana Marina dos. Uma breve análise acerca da crítica hermenêutica do direito frente aos desafios do multiculturalismo. Revista Eletrônica Direito e Política, Programa de Pós-Graduação Stricto Sensu em Ciência Jurídica da UNIVALI, Itajaí, v.16, n.2, $2^{\circ}$ quadrimestre de 2021. Disponível em: www.univali.br/direitoepolitica - ISSN 1980-7791.

mesmo sem nos darmos conta. Não há espaço para uma linguagem privada. Hermenêutica, no modo como eu trabalho, é antisolipsista. Por isso, o sentido do Direito será o que ele diz que é. E isso não é democrático.

Ainda, de acordo com Streck ${ }^{22}$, "o juiz não é dono dos sentidos. E nem os cria. Ele não é nem escravo dos sentidos e nem o seu dono. As constituições passam a ser normas: sim, um dever ser. Elas abarcam uma espécie de ideal de via boa". Logo, levado em conta o fato de que a hermenêutica reflete a responsabilidade e o compromisso com a constituição, quando o juiz não pode e não deve - ter poder de livre convencimento, cabe ao hermeneuta, deste modo, livrar-se da tentação de "chutar uma resposta", evitando, fundamentalmente, que a decisão dada por este seja objetivada por subjetividade, ideologia, ou, até mesmo, por seus próprios interesses pessoais.

Ocorre que, de acordo com Streck ${ }^{23}$, o Poder Judiciário se depara com decisões judiciais que nem sempre são democráticas, ou seja, decisões "nas quais o juiz procedeu de modo arbitrário, conforme a sua consciência individual, e isso é um desrespeito ao Estado Democrático de Direito que estabelece as regras do jogo qual o juiz atua". Verifica-se, então, que há um sério problema no que diz respeito aos atos interpretativos e discricionários aplicados por juízes quando chegado o momento de suas decisões, pois, para Streck ${ }^{24}$ :

[...] o juiz se encontra, quer queira quer não, submetido a um contexto intersubjetivo de significação em que os sentidos dos textos jurídicos (e dos fatos) com que lida não estão à disposição de sua livre apreciação para avaliá-los de maneira que ele, subjetivamente entende mais conveniente.

De acordo os desafios apresentados por Streck, é possível compreender que o hermeneuta possui grande responsabilidade quando da aplicação de sua decisão, mormente porque este, muitas vezes, não separa seu sentimento moral da aplicação de determinado preceito jurídico. Cumpre observar, neste sentido, que nem sempre as decisões do hermeneuta serão capazes de extrair o verdadeiro sentido e alcance da norma constitucional à luz de determinada sociedade.

\footnotetext{
22 STRECK, Lenio Luiz. Hermenêutica. p. 15.

${ }^{23}$ STRECK, Lenio Luiz. Hermenêutica. p. 24.

24 STRECK, Lenio Luiz. Hermenêutica. p. 25.
} 
SANTOS, Luana Marina dos. Uma breve análise acerca da crítica hermenêutica do direito frente aos desafios do multiculturalismo. Revista Eletrônica Direito e Política, Programa de Pós-Graduação Stricto Sensu em Ciência Jurídica da UNIVALI, Itajaí, v.16, n.2, $2^{\circ}$ quadrimestre de 2021. Disponível em: www.univali.br/direitoepolitica - ISSN 1980-7791.

Considerando que a noção de pluralismo jurídico se traduz ao reconhecimento da diversidade proveniente do multiculturalismo, já que este é capaz de originar a coexistência da interpretação de ordens jurídicas em um mesmo espaço geopolítico, verifica-se que "a diversidade de fontes do Direito e de perspectivas multiculturais que concorrem para dar sentido ao Direito, parecem, a princípio, transformar o Direito em algo heterogêneo e incoerente"25. Desta forma, o multiculturalismo, ao permitir que uma pluralidade de sociedades esteja sujeita ao mesmo texto legal, traduz aos juristas e aplicadores do Direito a necessidade de compreender que a Constituição necessita se amoldar aos valores contemporâneos que determinada sociedade regula, objetivando a possibilidade de se reinventar de acordo com todas as sociedades sem, no entanto, implicar em mudanças que enfraqueceriam ou deslegitimariam direitos e garantias constitucionais.

Isso porque, ainda que um mesmo território contenha uma vasta diversidade de opiniões acerca do conteúdo jurídico do texto normativo, um Estado democrático ainda tem o dever de propiciar uma convivência harmônica entre todos estes indivíduos, sem abdicar nenhum grupo da proteção e salvaguarda de direitos, especialmente Direitos Humanos e fundamentais.

Considerando, portanto, que a presença do multiculturalismo permite uma intensificação das diversas possibilidades de construção do sentido do Direito, dada a compreensão da existência de uma sociedade funcionalmente diferenciada e policêntrica, é possível também afirmar que o choque entre as culturas proporcionado pelo multiculturalismo nem sempre traz benefícios. Exemplo disso, é a dizimação dos povos indígenas em face à permanência da cultura hegemônica eurocêntrica, responsável por promover, direta e indiretamente, o desaparecimento de várias culturas indígenas desde a chegada do povo europeu às Américas ${ }^{26}$. Estas comunidades, por sua vez, ainda

25 CARVALHO, Meliza Marinelli Franco. Integridade e pluralismo jurídico: desafios para a hermenêutica constitucional brasileira. Revista Acadêmica da Faculdade de Direito do Recife, v. 90, n. 2, p. 96-121, jul./dez. 2018. p. 99. Disponível em: https://is.gd/ZfpiJj. Acesso em: 30 jan. 2020.

${ }^{26}$ BRAGATO, Fernanda Frizzo; NETO, Pedro Bigolin. Conflitos territoriais indígenas no Brasil: entre risco e prevenção. Revista Direito e Práxis, Rio de Janeiro, v. 8, n. 1, p. 156-195, 2017. Disponível em: https://is.gd/D7AE5U. Acesso em: 11 fev. 2020. 
SANTOS, Luana Marina dos. Uma breve análise acerca da crítica hermenêutica do direito frente aos desafios do multiculturalismo. Revista Eletrônica Direito e Política, Programa de Pós-Graduação Stricto Sensu em Ciência Jurídica da UNIVALI, Itajaí, v.16, n.2, $2^{\circ}$ quadrimestre de 2021. Disponível em: www.univali.br/direitoepolitica - ISSN 1980-7791.

permanecem sendo violentadas, inclusive pelo próprio governo brasileiro, demonstrando que o desaparecimento de culturas e o choque cultural é um movimento constante e presente durante todo o período da história da humanidade ${ }^{27}$.

Enfatiza-se que a proteção e promoção da diversidade das expressões culturais é de tamanha importância na medida em que se constitui indispensável para a paz e a segurança no plano nacional e internacional. No entanto, apesar deste discurso, cabe ressaltar que o simples reconhecimento da diversidade cultural não implica, necessariamente, em um espaço que promova esta pluralidade em um cenário sociopolítico. Priorizar a pluralidade das expressões culturais no mundo contemporâneo também pressupõe a instauração de políticas que efetivamente priorizem esta diversidade, em que seja possível a existência de um sistema que estabeleça determinada mediação entre as divergências provindas destes choques culturais, não apenas um discurso que reconheça a pluralidade de expressões culturais de um grupo de indivíduos ou de determinada comunidade.

Ocorre que as práticas culturais de determinados grupos, muitas vezes, violam a própria noção de direitos fundamentais, ou seja, algumas de suas práticas logram êxito em ferir a própria dignidade da pessoa humana e, mais além, a própria vida. Exemplo disso, é o caso do infanticídio indígena ${ }^{28}$. Todavia, de acordo com Streck ${ }^{29}$, "em nome de certo multiculturalismo ingênuo, alguns parlamentares e antropólogos têm se posicionado contra qualquer tipo de interferência do Estado em relação à prática desse comportamento". Neste sentido, cabe ao poder judiciário, aliado à prática hermenêutica, identificar em

\footnotetext{
27 BRAGATO, Fernanda Frizzo; NETO, Pedro Bigolin. Conflitos territoriais indígenas no Brasil: entre risco e prevenção. p. 156-195.

28 Prática cultural que ocorre em algumas tribos indígenas brasileiras, a qual vitima crianças de várias idades, em busca da preservação cultural da etnia. Em algumas tribos, a prática pode ser motivada pelo fato de a criança nascer com alguma deficiência física, filho de mãe solteira, ou gerado em uma relação de adultério, por exemplo. JESUS, Marcus Mendonça Gonçalves de; PEREIRA, Erick Wilson. Infanticídio indígena no Brasil: o conflito entre o direito à vida e à liberdade cultural e religiosa dos povos indígenas. Pensar - Revista de Ciências Jurídicas, Fortaleza, v. 22, n. 1, p. 353-380, jan./abr., 2017. Disponível em: https://is.gd/EkNgn5. Acesso em: 11 fev. 2020. ${ }^{29}$ STRECK, Lenio Luiz. A morte de crianças pode ser considerada uma questão cultural? Consultor Jurídico - Conjur, 29 out., 2015. Documento eletrônico. Disponível em: https://is.gd/EKB2tD. Acesso em: 30 jan. 2020.
} 
SANTOS, Luana Marina dos. Uma breve análise acerca da crítica hermenêutica do direito frente aos desafios do multiculturalismo. Revista Eletrônica Direito e Política, Programa de Pós-Graduação Stricto Sensu em Ciência Jurídica da UNIVALI, Itajaí, v.16, n.2, $2^{\circ}$ quadrimestre de 2021. Disponível em: www.univali.br/direitoepolitica - ISSN 1980-7791.

que medida a prática do infanticídio indígena pode ser gerida em uma sociedade que tem como princípio a proteção dos direitos e garantias fundamentais da criança, por exemplo.

Para Streck ${ }^{30}$,

[...] um multiculturalismo ingênuo, que naturaliza a morte de crianças (ou a ablação de mulheres na África), acaba caindo em um discurso puramente relativista e, mais tarde, encontra sérias dificuldades para apresentar argumentos consistentes em defesa dos direitos Humanos. Se a morte de crianças indígenas possui um sentido cultural para as comunidades que o praticam, é importante lembrar que as execuções do Estado Islâmico, motivadas pela ortodoxia religiosa, também o possui. Mutilação de partes femininas, idem. A situação é a seguinte: ou assumimos um discurso relativista e, portanto, aceitamos a normalização dessas práticas; ou abandonamos o relativismo e, assim, assumimos a integridade e a coerência como um ponto fundamental para a defesa dos direitos humanos.

Afinal, assim como questiona Streck, pode o infanticídio ser considerado como uma questão cultural? Esta breve pesquisa está longe de apresentar respostas para esta pergunta, uma vez que esta temática implica em uma série de observações relativas à comunidade na qual ela será aplicada. No entanto, cumpre esclarecer que o exemplo aqui demonstrado é capaz de refletir a importância da hermenêutica na comunidade jurídica e social, cabendo, pois, aos intérpretes do Direito identificar de que maneira pode ser possível conciliar o multiculturalismo com as práticas culturais destas e outras comunidades. Para isso, observar-se-á, no próximo capítulo, a concepção apresentada por Lenio Streck, esta, por sua vez, baseada, entre outros, em Ronald Dworkin, a fim de apresentar aportes específicos que objetivem discorrer acerca da aplicação do Direito em sociedades contemporâneas multiculturais, com o objetivo de evitar a prática discricionária do intérprete.

30 STRECK, Lenio Luiz. A morte de crianças pode ser considerada uma questão cultural? Consultor Jurídico - Conjur, 29 out., 2015. Documento eletrônico. Disponível em: https://is.gd/EKB2tD. Acesso em: 30 jan. 2020. 
SANTOS, Luana Marina dos. Uma breve análise acerca da crítica hermenêutica do direito frente aos desafios do multiculturalismo. Revista Eletrônica Direito e Política, Programa de Pós-Graduação Stricto Sensu em Ciência Jurídica da UNIVALI, Itajaí, v.16, n.2, $2^{\circ}$ quadrimestre de 2021. Disponível em: www.univali.br/direitoepolitica - ISSN 1980-7791.

\section{A CRÍtICA HERMENÊUTICA JURÍdiCA DIANTE DAS IMPLICAÇõES JURÍDICAS DO MULTICULTURALISMO}

Considerando que esta pesquisa, até a presente seção, procurou identificar o desafio da hermenêutica jurídica em aplicar o Direito, principalmente quando se encontra presente uma vasta gama de divergências morais que implicam, como já abarcado, em diferenças no que concerne às questões de religião, sexualidade, gênero, política e, inclusive, no que diz respeito aos fundamentos de uma decisão judicial. Baseando-se nos aportes teóricos de Lenio Streck, e Ronald Dworkin, procurar-se-á problematizar, por fim, o desafio do multiculturalismo na comunidade jurídica, objetivando, essencialmente, a salvaguarda de garantias constitucionais fundamentais.

Ao contrário de Hart ${ }^{31}$, para Dworkin ${ }^{32}$, o juiz, ao se deparar com a inexistência de determinada lei para aplicar ao caso concreto, deve valer-se da utilização de um conjunto de princípios para a melhor interpretação da estrutura política naquela comunidade. No entanto, de acordo com Streck ${ }^{33}$, é primordial ter muito cuidado com a "construção" destes princípios, pois, ainda que os princípios sirvam para resolver determinados problemas provenientes de casos difíceis, os mesmos deverão servir para fechar a interpretação do hermeneuta, e não abrir a interpretação jurídica.

No que tange à interpretação jurídica, de acordo com Dworkin ${ }^{34}$, quando o hermeneuta se encontra mediante a algum caso de difícil solução, este deverá empregar padrões que percorram a aplicação de princípios. Para Dworkin ${ }^{35}$,

\footnotetext{
31 Para Hart, a discricionariedade seria vital, pois as normas possuem textura aberta. Esta característica seria arraigada à norma, tendo em vista a impossibilidade, na estratégia escolhida, para a transmissão de padrões de comportamento prever todas as situações possíveis, seja o precedente ou a legislação. Na visão de Hart, diante desta incompletude e textura aberta, torna-se necessário, em casos não regulamentados juridicamente, os tribunais exercerem a função legislativa limitada denominada discricionariedade. HART, Herbert. O Conceito de Direito. São Paulo: Martins Fontes, 2009.

32 DWORKIN, Ronald. O império do Direito. Tradução de Jefferson Luiz Camargo. 2 ed. São Paulo: Martins Fontes, 2007.

33 STRECK, Lenio Luiz. Dicionário de Hermenêutica: quarenta temas fundamentais da teoria do Direito à luz da hermenêutica do Direito. Belo Horizonte: Letramento, 2017.

34 DWORKIN, Ronald. O império do Direito. Tradução de Jefferson Luiz Camargo. 2 ed. São Paulo: Martins Fontes, 2007.

35 DWORKIN, Ronald. O império do Direito. Tradução de Jefferson Luiz Camargo. 2 ed. São Paulo: Martins Fontes, 2007.
} 
SANTOS, Luana Marina dos. Uma breve análise acerca da crítica hermenêutica do direito frente aos desafios do multiculturalismo. Revista Eletrônica Direito e Política, Programa de Pós-Graduação Stricto Sensu em Ciência Jurídica da UNIVALI, Itajaí, v.16, n.2, $2^{\circ}$ quadrimestre de 2021. Disponível em: www.univali.br/direitoepolitica - ISSN 1980-7791.

princípios são diferentes de regras, pois o primeiro, ao contrário do segundo, que contempla ou não contempla a situação do mundo da vida, protagoniza a dimensão do peso ou da importância. Sobre este aspecto, afirma Streck ${ }^{36}$, que princípios definitivamente não são normas, tampouco valores ou atos que podem ser inventados, no entanto, muitas vezes, "quando a regra (lei) não é justa ou não Ihe agrada pessoalmente, o juiz pós-positivista passa a lançar mão de qualquer coisa, inclusive inventando axiomas subjetivistas que levam o nome de 'princípio'. Resultado: uma hecatombe". Ou seja, o jurista passa a moralizar as leis e o próprio Direito, muitas vezes, passando por cima de leis votadas e aprovadas de maneira democrática.

Ainda, de acordo com Streck ${ }^{37}$, "quando nos movemos no mundo do sentido, compreendendo e interpretando, não o fazemos a partir de nossa consciência apartada do mundo". Isso porque, os sentidos não necessariamente partem da consciência de quem o interpreta, "mas, sim, de sua inserção em um mundo repleto de significados compartilhados intersubjetivamente ${ }^{38 " .}$ Aí se insere o importante papel dos princípios no intuito de combater a discricionariedade daquele que interpreta os sentidos do mundo.

Somando-se à ideia da utilização de princípios, e objetivando identificar um suporte de padrões para as decisões dadas pelo julgador em casos difíceis, especialmente em casos nos quais há convergências de semântica, aliada à Filosofia Hermenêutica (Heidegger), à hermenêutica filosófica (Gadamer) e, substancialmente, no plano da teoria do direito, aos aportes da teoria integrativa de Dworkin, é que se constitui a Crítica Hermenêutica do Direito (CHD), atuante como oposição à discricionariedade e ao ativismo judicial ${ }^{39}$.

Heidegger, Gadamer e Dworkin contribuem enquanto cosmovisão básica para constituir a teoria de Lenio Streck, a qual objetiva, de certa forma, auxiliar na

\footnotetext{
36 STRECK, Lenio Luiz. Hermenêutica. p. 26.

37 STRECK, Lenio Luiz; OLIVEIRA, Rafael Tomaz de. O que é isto? A hermenêutica jurídica. Consultor Jurídico - Conjur, 29 ago., 2015. Documento eletrônico. Disponível em: https://is.gd/7bkJ9a. Acesso em: 31 jan. 2020.

38 STRECK, Lenio Luiz; OLIVEIRA, Rafael Tomaz de. O que é isto? A hermenêutica jurídica. Consultor Jurídico - Conjur, 29 ago., 2015. Documento eletrônico. Disponível em: https://is.gd/7bkJ9a. Acesso em: 31 jan. 2020.

39 STRECK, Lenio Luiz. Hermenêutica. Livro carta. p. 26.
} 
SANTOS, Luana Marina dos. Uma breve análise acerca da crítica hermenêutica do direito frente aos desafios do multiculturalismo. Revista Eletrônica Direito e Política, Programa de Pós-Graduação Stricto Sensu em Ciência Jurídica da UNIVALI, Itajaí, v.16, n.2, $2^{\circ}$ quadrimestre de 2021. Disponível em: www.univali.br/direitoepolitica - ISSN 1980-7791.

aplicação de casos que não tenham uma solução direta (de fácil aplicação). Os aportes de Streck, por consequência, auxiliam a forma de aplicar o Direito diante dos problemas apontados, muitos deles pautados pela discricionariedade do exegeta em uma sociedade tão plural quanto a da realidade brasileira.

Streck ${ }^{40}$ explica que a Crítica Hermenêutica do Direito tem como ponto de partida o fato de que há decisões judicias que não são democráticas, abrindo espaço para um problema que se constitui na medida da aplicação do ato interpretativo do juiz no momento de sua decisão. Assim, procura a CHD, substancialmente, despertar a comunidade jurídica acerca da discricionariedade e de seus derivados genéricos. Desta forma, explica Streck, que há ênfase na necessidade de uma teoria da decisão.

Conforme já observado, é importante lembrar que toda e qualquer decisão deve ser entendida como um processo que requer, acima de tudo, responsabilidade política, não podendo esta, por si só, ser compreendida por uma escolha personalista. No entanto, como bem observado por Streck ${ }^{41}$, não existe um "grau zero de sentidos", razão pela qual a hermenêutica "não proíbe que se trabalhe em um nível lógico ou argumentativo, mas sabe que há uma dimensão interpretativa ou existencial que antecede e que é condição de possibilidade para qualquer discurso".

Neste sentido, Streck aponta para a importância dos princípios ${ }^{42}$, uma vez que estes servem para fechar a interpretação jurídica. Poder-se-ia dizer, dessa forma, que não há cisão estrutural entre regras e princípios, uma vez que da mesma maneira, nos casos em que deve ser aplicada a literalidade da regra, isso só é possível porque ela vem justificada por um princípio que the sustenta ${ }^{43}$. Assim, considerando que a Constituição Federal Brasileira de $1988^{44}$ prevê a salvaguarda de direitos e garantias fundamentais, ainda que o aplicador se

40 STRECK, Lenio Luiz. Hermenêutica. Livro carta. p. 21.

${ }^{41}$ STRECK, Lenio Luiz. Hermenêutica. Livro carta. p. 22.

42 Para o autor, os princípios deverão ser sempre normativos no combate à discricionariedade proposta pela CHD. STRECK, Lenio Luiz. Hermenêutica. Livro carta. São Leopoldo: Edição do autor, 2017.

43 STRECK, Lenio Luiz. Dicionário de Hermenêutica: quarenta temas fundamentais da teoria do Direito à luz da hermenêutica do Direito. Belo Horizonte: Letramento, 2017.

44 BRASIL. Constituição da República Federativa do Brasil de 1988. Brasília, DF, 1988. Disponível em: https://is.gd/Q7arPx. Acesso em: 11 fev. 2020. 
SANTOS, Luana Marina dos. Uma breve análise acerca da crítica hermenêutica do direito frente aos desafios do multiculturalismo. Revista Eletrônica Direito e Política, Programa de Pós-Graduação Stricto Sensu em Ciência Jurídica da UNIVALI, Itajaí, v.16, n.2, $2^{\circ}$ quadrimestre de 2021. Disponível em: www.univali.br/direitoepolitica - ISSN 1980-7791.

encontre em uma situação difícil, explica o autor, que estes dispositivos só poderão deixar de aplicados em hipóteses específicas, quais sejam:

a) quando se tratar de inconstitucionalidade; b) quando for o caso de aplicação dos critérios de resolução de antinomias; c) quando aplicar a interpretação conforme a Constituição; d) quando aplicar a nulidade parcial sem redução de texto; e) quando for o caso de declaração de inconstitucionalidade com redução de texto; f) quando deixar de aplicar uma regra em face de um princípio, entendidos esses como não standards teóricos ou enunciados performativos ${ }^{45}$.

Para Streck, as hipóteses apresentadas trariam mais segurança quando da aplicação da norma jurídica. Certa previsibilidade que, para o jurista, deve ser proveniente do direito, e não da moral. Ainda, para $\operatorname{Streck}^{46}$, as seis hipóteses solidificam uma certa "blindagem contra-argumentos exógenos que, se utilizados como critérios de fundamentação das decisões, passam a flexibilizar e relativizar as disposições constitucionais". Neste sentido, compreende-se que estas hipóteses também serviriam para garantir a aplicabilidade de direitos e garantias fundamentais, ainda em casos em que surja a dificuldade de interpretação por parte do jurista, situação corriqueira em sociedades protagonizadas pelo multiculturalismo.

Vale ressaltar que, ainda que o jurista incorpore, de certa forma, a teoria de Dworkin $^{47}$ - no que diz respeito à busca pela resposta correta ${ }^{48}$, Streck $^{49}$ explica que, em verdade, é preciso que se busque "a" resposta correta, nem a única, e nem uma entre várias. Esclarece-se: ao lado da justiça e do devido processo

\footnotetext{
45 STRECK, Lenio Luiz. Hermenêutica. Livro carta. p. 27.

46 STRECK, Lenio Luiz. Hermenêutica. Livro carta. p. 27.

47 DWORKIN, Ronald. Levando os Direitos a Sério. Tradução de Nelson Boeira. 3 ed. São Paulo: Martins Fontes, 2011.

48 A tese da resposta correta ganhou projeção na teoria do direito a partir da crítica de Ronald Dworkin à discricionariedade do positivismo de Herbert Hart, afirmando que, mesmo nos chamados casos difíceis (hard cases), a justificativa política do processo está em que as partes possuam direito a uma decisão específica. MARINHO, Jefferson Luiz Alves. Teoria da integridade de Ronald Dworkin: um olhar matemático para a tese da resposta correta. In: XI SEMINÁRIO NACIONAL DEMANDAS SOCIAIS E POLÍTICAS PÚBLICAS NA SOCIEDADE CONTEMPORÂNEA, 11., 2015, Santa Catarina. Anais... [...]. Santa Catarina: Unisc, 2015. Disponível em: https://is.gd/uQtAtH. Acesso em: 11 fev. 2020.

49 STRECK, Lenio Luiz. Hermenêutica. Livro carta. p. 28.
} 
SANTOS, Luana Marina dos. Uma breve análise acerca da crítica hermenêutica do direito frente aos desafios do multiculturalismo. Revista Eletrônica Direito e Política, Programa de Pós-Graduação Stricto Sensu em Ciência Jurídica da UNIVALI, Itajaí, v.16, n.2, $2^{\circ}$ quadrimestre de 2021. Disponível em: www.univali.br/direitoepolitica - ISSN 1980-7791.

legal, a integridade, para Dworkin ${ }^{50}$, sugere que "o governo, de modo coerente e fundamentado em princípios com todos os seus cidadãos, estenda, a cada um, padrões fundamentais de justiça e equidade". Dessa forma, a integridade se constitui como parte da moral política coletiva, na qual a comunidade, como um todo, atua de acordo com os princípios moralmente coerentes. Para Dworkin ${ }^{51}$ : "[...] uma sociedade política que aceita a integridade como virtude política se transforma, desse modo, em uma forma especial de comunidade, num sentido que promove sua autoridade moral para assumir e mobilizar o monopólio de força coercitiva".

Para Carvalho52, é possível observar que o Direito como integridade,

[...] resgata a crença no valor e na unidade do Direito (por isso visa promover a coerência das decisões jurídicas: as decisões são coerentes na medida em que expressam a unidade do Direito). Mas essa unidade do Direito, da maneira como Dworkin apresenta, comporta diferentes formas de expressão da pluralidade de uma sociedade.

No entanto, Streck ${ }^{53}$ adverte que é necessário que a Constituição tenha, verdadeiramente, força normativa, ou seja, que a hermenêutica jurídica se mostre verdadeiramente compromissada com os preceitos constitucionais, ainda em casos em que haja dificuldade na tomada de decisões, como os que acontecem em sociedades tão plurais e marcadas pela intersecção de culturas. Compreende-se, dessa maneira, a necessidade de que haja "a" resposta concreta, analisada caso por caso, e não uma resposta específica para todos, a fim de que o direito possa, efetivamente, corresponder a todas as problemáticas trazidas pelo multiculturalismo.

\footnotetext{
50 DWORKIN, Ronald. 0 império do Direito. Tradução Jefferson Luiz Camargo. 2 ed. São Paulo: Martins Fontes, 2007. p. 202.

51 DWORKIN, Ronald. O império do Direito. p. 227.

52 CARVALHO, Meliza Marinelli Franco. Integridade e pluralismo jurídico: desafios para a hermenêutica constitucional brasileira. Revista Acadêmica da Faculdade de Direito do Recife, v. 90, n. 2, p. 96-121, jul./dez. 2018. p. 100. Disponível em: https://is.gd/ZfpiJj. Acesso em: 31 jan. 2020.

53 STRECK, Lenio Luiz. Dicionário de Hermenêutica: quarenta temas fundamentais da teoria do Direito à luz da hermenêutica do Direito. Belo Horizonte: Letramento, 2017.
} 
SANTOS, Luana Marina dos. Uma breve análise acerca da crítica hermenêutica do direito frente aos desafios do multiculturalismo. Revista Eletrônica Direito e Política, Programa de Pós-Graduação Stricto Sensu em Ciência Jurídica da UNIVALI, Itajaí, v.16, n.2, $2^{\circ}$ quadrimestre de 2021. Disponível em: www.univali.br/direitoepolitica - ISSN 1980-7791.

A interpretação de Streck $^{54}$ permite compreender que na medida em que haja a existência de perspectivas multiculturais, também coexista a possibilidade de mantimento e salvaguarda de determinados direitos, e que haja, de fato, um comprometimento com a Constituição, analisando cada caso em sua particularidade.

Compreender que a presença do multiculturalismo permite uma intensificação das diversas possibilidades de construção do sentido do Direito, dada a compreensão da existência de uma sociedade funcionalmente diferenciada e policêntrica, é passo fundamental para identificar que a aplicação do Direito desafia, cada vez mais, a prática da hermenêutica jurídica, especialmente quando o problema da moralidade interfere na aplicabilidade de garantias constitucionais. Neste sentido, cabe considerar, também, que a aplicação destes direitos e garantias se mostra essencial no que tange à salvaguarda da Constituição Federal Brasileira, mesmo que em casos difíceis.

Como já observado, este breve trabalho não teve como meta oferecer certezas, mas sim percorrer argumentos para verificar em que medida a crítica hermenêutica do Direito, proposta por Lenio Streck, se mostra apta a, talvez, direcionar um método de aplicação da hermenêutica jurídica compatível à pluralidade das sociedades, objetivando, substancialmente, salvaguardar direitos e garantias fundamentais, ainda que em uma sociedade marcada pelos desafios provenientes do multiculturalismo.

\section{CONSIDERAÇÕES FINAIS}

Durante o curso deste trabalho, restou possível observar, em um primeiro momento, que o multiculturalismo logra êxito em abarcar a existência e, consequentemente, a convivência de diversas culturas em um mesmo território nacional. A diferença entre um grupo e outro protagoniza as divergências de interpretação no que diz respeito à religião, à política, à sexualidade e ao gênero,

\footnotetext{
${ }^{54}$ STRECK, Lenio Luiz. Hermenêutica. Livro carta. p. 31.
} 
SANTOS, Luana Marina dos. Uma breve análise acerca da crítica hermenêutica do direito frente aos desafios do multiculturalismo. Revista Eletrônica Direito e Política, Programa de Pós-Graduação Stricto Sensu em Ciência Jurídica da UNIVALI, Itajaí, v.16, n.2, $2^{\circ}$ quadrimestre de 2021. Disponível em: www.univali.br/direitoepolitica - ISSN 1980-7791.

à educação e, também, no que tange à derivação do conteúdo formal de direitos e garantias fundamentais.

Observou-se, ainda, que a prática da hermenêutica jurídica possui relevante importância no que diz respeito à salvaguarda destes mesmos direitos e garantias, na medida em que também procura desempenhar o papel de reconhecer a diferença e estabelecer diálogo entre os grupos. Do mesmo modo, ressaltou-se a problemática apresentada pela aplicação da hermenêutica jurídica pelo intérprete, principalmente quando este não logra êxito em desvincular decisões interpretativas pautadas por sua moralidade pessoal ou por seus próprios interesses, dando espaço para decisões arbitrárias em que não haja observância dos valores prescritos na Constituição Federal, bem como proporcionando a inobservância de uma ordem jurídica apta a tutelar os mais diferentes interesses e necessidades das sociedades multiculturais.

Considerando de suma importância que seja observado o contexto de cada caso de acordo com o histórico sociológico de cada grupo social, respeitando e observando as dimensões multiculturais; considerando, ainda, a importância da salvaguarda de direitos e garantias fundamentais, ressaltou-se, na última seção do artigo, de que maneira o pensamento proposto por Lenio Streck pode propiciar uma harmonização destas divergências, constituindo, a partir dos aportes apresentados, a possibilidade de um ambiente próspero para a coexistência de várias formas de cultura em um mesmo território, sem a ausência de direitos e garantias assegurados constitucionalmente.

\section{REFERÊNCIAS DAS FONTES CITADAS}

BRAGATO, Fernanda Frizzo; NETO, Pedro Bigolin. Conflitos territoriais indígenas no Brasil: entre risco e prevenção. Revista Direito e Práxis, Rio de Janeiro, v. 8, n. 1, p. 156-195, 2017. Disponível em: https://is.gd/D7AE5U. Acesso em: 11 fev. 2020.

BRASIL. Constituição da República Federativa do BrasiL de 1988. Brasília, DF, 1988. Disponível em: https://is.gd/Q7arPx. Acesso em: 11 fev. 2020. 
SANTOS, Luana Marina dos. Uma breve análise acerca da crítica hermenêutica do direito frente aos desafios do multiculturalismo. Revista Eletrônica Direito e Política, Programa de Pós-Graduação Stricto Sensu em Ciência Jurídica da UNIVALI, Itajaí, v.16, n.2, $2^{\circ}$ quadrimestre de 2021. Disponível em: www.univali.br/direitoepolitica - ISSN 1980-7791.

CARVALHO, Meliza Marinelli Franco. Integridade e pluralismo jurídico: desafios para a hermenêutica constitucional brasileira. Revista Acadêmica da Faculdade de Direito do Recife, v. 90, n. 2, p. 96-121, jul./dez. 2018. Disponível em: https://is.gd/ZfpiJj. Acesso em: 30 jan. 2020.

DWORKIN, Ronald. Levando os Direitos a Sério. Tradução de Nelson Boeira. 3 ed. São Paulo: Martins Fontes, 2011.

DWORKIN, Ronald. O império do Direito. Tradução de Jefferson Luiz Camargo. 2 ed. São Paulo: Martins Fontes, 2007.

FORTUNA, Deborah; SOARES, Ingrid. Pobreza no Brasil não está ligada apenas a questões financeiras. Correio Braziliense, 15 ago., 2018. Disponível em: https://is.gd/jpptyS. Acesso em: 9 fev. 2020.

HAAS, Ingrid Freire. Multiculturalismo na atualidade: o direito à cultura e sua expressão nos direitos humanos. Revista Eletrônica do Curso de Direito PUC Minas Serro, n. 5, p. 105-127, 2012. Disponível em: https://is.gd/drIXin. Acesso em: 9 fev. 2020.

HART, Herbert. O Conceito de Direito. São Paulo: Martins Fontes, 2009.

JESUS, Marcus Mendonça Gonçalves de; PEREIRA, Erick Wilson. Infanticídio indígena no Brasil: o conflito entre o direito à vida e à liberdade cultural e religiosa dos povos indígenas. Pensar - Revista de Ciências Jurídicas, Fortaleza, v. 22, n. 1, p. 353-380, jan./abr., 2017. Disponível em: https://is.gd/EkNgn5. Acesso em: 11 fev. 2020.

MARINHO, Jefferson Luiz Alves. Teoria da integridade de Ronald Dworkin: um olhar matemático para a tese da resposta correta. In: XI SEMINÁRIO NACIONAL DEMANDAS SOCIAIS E POLÍTICAS PÚBLICAS NA SOCIEDADE CONTEMPORÂNEA, 11., 2015, Santa Catarina. Anais... [...]. Santa Catarina: Unisc, 2015. Disponível em: https://is.gd/uQtAtH. Acesso em: 11 fev. 2020.

PEREIRA, Mychelli Araújo de Oliveira. A questão dos direitos fundamentais na atual sociedade multiculturalista. Revista Jurídica ESMP-SP, v.4, p. 43-58, 2013. Disponível em: https://is.gd/VuYv1K. Acesso em: 30 jan. 2020.

REALE, Miguel. Fontes e modelos do Direito: para um novo paradigma hermenêutico. São Paulo: Saraiva, 1994.

SANTOS, Boaventura de Souza. Por uma concepção multicultural de direitos humanos. Revista Crítica de Ciências Sociais, n. 48, p. 11-32, jun., 1997. Disponível em: https://is.gd/b73AxS. Acesso em: 9 fev. 2020.

SANTOS, Boaventura de Sousa. (Org.). Reconhecer para libertar. Os caminhos do cosmopolitismo multicultural. Porto, Portugal: Edições Afrontamento, 2004. 
SANTOS, Luana Marina dos. Uma breve análise acerca da crítica hermenêutica do direito frente aos desafios do multiculturalismo. Revista Eletrônica Direito e Política, Programa de Pós-Graduação Stricto Sensu em Ciência Jurídica da UNIVALI, Itajaí, v.16, n.2, $2^{\circ}$ quadrimestre de 2021. Disponível em: www.univali.br/direitoepolitica - ISSN 1980-7791.

STRECK, Lenio Luiz. A morte de crianças pode ser considerada uma questão cultural? Consultor Jurídico - Conjur, 29 out., 2015. Documento eletrônico. Disponível em: https://is.gd/EKB2tD. Acesso em: 30 jan. 2020.

STRECK, Lenio Luiz. Dicionário de Hermenêutica: quarenta temas fundamentais da teoria do Direito à luz da hermenêutica do Direito. Belo Horizonte: Letramento, 2017.

STRECK, Lenio Luiz. Hermenêutica jurídica $\mathbf{e ( m )}$ crise: uma exploração hermenêutica da construção do Direito. Porto Alegre: Editora Livraria do Advogado, 2005.

STRECK, Lenio Luiz. Hermenêutica. Livro carta. São Leopoldo: Edição do autor, 2017.

STRECK, Lenio Luiz. Jurisdição Constitucional e Hermenêutica: uma nova crítica do Direito. Rio de Janeiro: Editora Forense, 2004.

STRECK, Lenio Luiz; OLIVEIRA, Rafael Tomaz de. O que é isto? A hermenêutica jurídica. Consultor Jurídico - Conjur, 29 ago., 2015. Documento eletrônico. Disponível em: https://is.gd/7bkJ9a. Acesso em: 31 jan. 2020.

RECEBIDO EM: MAI/2020

APROVADO EM: ABR/2021 